Baseline

\title{
Distribution, enrichment and sources of thallium in the surface sediments of the southwestern coastal Laizhou Bay, Bohai Sea
}

\author{
Wen Zhuang ${ }^{\mathrm{a}, \mathrm{b}}$, Xuelu Gao ${ }^{\mathrm{a}, *}$ \\ ${ }^{a}$ Key Laboratory of Coastal Environmental Processes and Ecological Remediation, Yantai Institute of Coastal Zone Research, Chinese Academy of Sciences, Yantai, Shandong \\ 264003, China \\ ${ }^{\mathrm{b}}$ College of City and Architecture Engineering, Zaozhuang University, Zaozhuang, Shandong 277160, China
}

\section{A R T I C L E I N F O}

\section{Article history:}

Available online 27 April 2015

\section{Keywords:}

Heavy metal

Potential harmful element

Priority pollutant

Sediment analysis

Marine environment

Geochemical characteristics

\begin{abstract}
A B S T R A C T
The concentrations of thallium ( $\mathrm{Tl}$ ) in the surface sediments of the southwestern coastal Laizhou Bay and the rivers it connects were determined. In riverine sediments, the $\mathrm{Tl}$ concentrations ranged from 0.34 to $0.76 \mu \mathrm{g} \mathrm{g}^{-1}$ in summer; in autumn, the corresponding data were $0.35-1.08 \mu \mathrm{g} \mathrm{g}^{-1}$. In marine sediments, the $\mathrm{Tl}$ concentrations ranged from 0.36 to $0.58 \mu \mathrm{g} \mathrm{g}^{-1}$ in summer; and from 0.30 to $0.56 \mu \mathrm{g} \mathrm{g}^{-1}$ in autumn. The grain size, Al and Fe oxides were major factors affecting Tl distribution. Tl in the surface sediments of the studied area was mainly from the natural input with the non-natural input as a subsidiary source. The low concentrations of Tl made it hard to cause potential negative environmental effects in this area.
\end{abstract}

(c) 2015 Elsevier Ltd. All rights reserved.
Thallium ( $\mathrm{Tl}$ ) is a naturally occurring bioaccumulative element widely distributing in the environment. $\mathrm{Tl}$ is not found in the elemental state in nature; it is not an essential element of life and performs no function in the metabolism of organisms, and its compounds are often highly toxic. Tl is widely used in industry in modern days. Studies have shown that the acute toxicity of $\mathrm{Tl}$ to mammals is higher than that of some heavy metals which are well known to the general public such as $\mathrm{Cd}, \mathrm{Cu}, \mathrm{Hg}, \mathrm{Pb}$ and $\mathrm{Zn}$ (Cheam, 2001), and its toxicity to plants is even higher (Hsieh et al., 2004). So, $\mathrm{Tl}$ is one of the 13 chemical elements that have been included in the USEPA list of priority pollutants (USEPA, 1979). Nonetheless, $\mathrm{Tl}$ has received less attention in environmental research compared with those elements that are used to assess environmental quality. Up to now, literature on the occurrence, behavior and fate of this potentially harmful element in aquatic systems is hardly found.

Sediments are a natural and essential part of aquatic environments. They are one of the dynamic components of hydrologic cycle which links terrestrial, freshwater and marine ecosystems. They also play key roles in a wide variety of human activities that impact on aquatic systems. Both freshwater and marine sediments are widely sampled and analyzed in environmental monitoring and

\footnotetext{
* Corresponding author at: Key Laboratory of Coastal Environmental Processes and Ecological Remediation, Yantai Institute of Coastal Zone Research, Chinese Academy of Sciences, 17 Chunhui Road, Yantai, Shandong 264003, China. Tel.: +86 535 2109132; fax: +865352109000.

E-mail address: xlgao@yic.ac.cn (X. Gao).
}

assessment programs because they can reflect environmental quality well. Pollutants in sediments not only could cause negative effects on benthic ecosystems through a variety of ways, but also could be released into the overlying water under certain conditions, which could become a secondary pollution of water column and impose potential biological toxicity.

The Laizhou Bay is one of the three major bays in the Bohai Sea, making up $\sim 10 \%$ of its total areas, with a coastline length of $\sim 320 \mathrm{~km}$ and a surface area of $\sim 7000 \mathrm{~km}^{2}$. It used to be one of the most important spawning and breeding grounds for many marine organisms in China. There are over a dozen rivers flowing into the Laizhou Bay mainly from its southwestern coast such as the Guanglihe River, the Xiaoqinghe River, the Bailanghe River and so on. Over 400 chemical enterprises are located along the southwestern coastline of the Laizhou Bay, forming one of the biggest manufacturing bases for chlor-alkali products in the world. One of the country's largest oil fields, Shengli Oil Field (in Dongying City), was located in the west coast of the Laizhou Bay. In recent years, the Laizhou Bay is under unprecedented threats from the rapid urbanization and industrialization, overfishing and overexploitation of the coastline.

An investigation of the surface sediment quality and the geochemical behaviors of trace elements was carried out in the southwestern coastal Laizhou Bay in 2012, covering its infralittoral zone and the lowermost areas of the major rivers to which it connects, and related papers have been published concerning that investigation (Zhuang and Gao, 2013, 2014a; Gao et al., 2015). 
The objectives of this work were to quantify and explore the spatial distribution characteristic of $\mathrm{Tl}$ in the surface sediments of the southwestern coastal Laizhou Bay and evaluate the responses of $\mathrm{Tl}$ to the anthropogenic effects from the surrounding areas.

The field sampling work of this research was carried out twice in 2012: early summer (May-June, hereafter referred to as summer for short), which was before the peak period of the rainy season, and middle autumn (September-October, hereafter referred to as autumn for short), which was after the peak period of the rainy season. The sampling sites were arranged along the major rivers of this area extending from the land to the sea and formed five transects, covering about $15-20 \mathrm{~km}$ from the high tide mark to the land and about $10 \mathrm{~km}$ from the high tide mark to the sea (Fig. 1; Zhuang and Gao, 2013; Gao et al., 2015). The riverine surface sediments were collected using a plastic spatula from the shallow water near to the riverside, and the marine surface sediments were collected with a stainless steel grab sampler. The samples used in this study were placed in acid cleaned polyethylene bags, and stored in a cooler box with ice bags immediately after the collection. When taken back to the lab, the samples were stored at $\sim 4{ }^{\circ} \mathrm{C}$ in the dark until analyses were made. A total of 52 surface sediment samples (top $\sim 5 \mathrm{~cm}$ ) collected in summer and 47 collected in autumn were treated for the $\mathrm{Tl}$ analysis.

The concentration of $\mathrm{Tl}$ in each sample was obtained by digesting an aliquot of freeze-dried, homogenized and ground sediment with the mixture of concentrated $\mathrm{HF}, \mathrm{HNO}_{3}$ and $\mathrm{HClO}_{4}(5: 2: 1)$ (Gao et al., 2010). Inductively coupled plasma mass spectrometry (PerkinElmer Elan DRC II) was applied in this work for the determination of $\mathrm{Tl}$. In addition, the concentrations of $\mathrm{Al}$ and Fe were analyzed by inductively coupled plasma optical emission spectrometer (PerkinElmer Optima $7000 \mathrm{DV}$ ) and the enrichment factor (EF) of Tl was calculated using Al.

Analytical methods and results of the total organic carbon (TOC) and grain size of the samples have been described in our previous publications (Zhuang and Gao, 2013; Zhuang and Gao, 2014a, 2014b; Zhuang et al., 2014). The substance concentrations in the sediments were expressed on the dry weight basis based on the results of moisture content.

The analytical data quality was guaranteed through the implementation of laboratory quality assurance and quality control methods, including the use of standard operating procedures, calibration with standards, analysis of reagent blanks, and analysis of replicates. The precision of the analysis of standard solution (RSD) was better than 5\%. All analyses were carried out in duplicate, and the results were expressed as the mean. The quality of the analytical procedures was tested by recovery measurements on the Chinese national geostandard samples (GBW-07309 and GBW-07334). The results were consistent with the reference values, the differences all within $\pm 10 \%$. All reagents were guaranteed grade or higher level. All the labwares (bottles, tubes, etc.) were pre-cleaned by soaking in $10 \% \mathrm{HNO}_{3}(\mathrm{w} / \mathrm{w})$ for at least 2 days, followed by soaking and rinsing with de-ionized water.

The spatial variations of $\mathrm{Tl}$ in the surface sediments of the Laizhou Bay are shown in Fig. 2. In riverine sediments, in summer, the $\mathrm{Tl}$ concentrations ranged from 0.34 to $0.76 \mu \mathrm{g} \mathrm{g}^{-1}$, with an average of $0.45 \mu \mathrm{g} \mathrm{g}^{-1}$; in autumn, the corresponding data were $0.35-1.08 \mu \mathrm{g} \mathrm{g}^{-1}$ and $0.47 \mu \mathrm{g} \mathrm{g}^{-1}$, respectively. In marine sediments, in summer, the $\mathrm{Tl}$ concentrations ranged from 0.36 to $0.58 \mu \mathrm{g} \mathrm{g}^{-1}$, with an average of $0.42 \mu \mathrm{g} \mathrm{g}^{-1}$; in autumn, the corresponding data were $0.30-0.56 \mu \mathrm{g} \mathrm{g}^{-1}$ and $0.44 \mu \mathrm{g} \mathrm{g}^{-1}$, respectively. The $\mathrm{Tl}$ concentrations exhibited a small fluctuation among the sites with the highest value at site GLH3 and the lowest value at site K2 in autumn. Unlike those metals suffering from severe anthropogenic impacts, the concentrations of which in coastal sediments usually show a decreasing seaward trend, the mean concentrations of $\mathrm{Tl}$ in riverine sediments in both seasons were comparable to its corresponding values in marine sediments, reflecting a weak anthropogenic impact on the spatial distribution of sedimentary $\mathrm{Tl}$ in the studied area.

The mean concentrations of $\mathrm{Tl}$ in both marine and riverine sediments were higher than its mean value in the sediments of Chinese shallow waters $\left(0.30 \mu \mathrm{g} \mathrm{g}^{-1}\right)$, but lower than its mean values in the Chinese soils $\left(0.58 \mu \mathrm{g} \mathrm{g}^{-1}\right)$ and terrestrial sediments $\left(0.55 \mu \mathrm{g} \mathrm{g}^{-1}\right)$ (Gao et al., 2008). In addition, they were very close to the reported $\mathrm{Tl}$ value in the Yellow River sediment $\left(0.45 \mu \mathrm{g} \mathrm{g}^{-1}\right)$ (Gao et al., 2008). According to the above comparison, Tl in the surface sediments of the southwestern coastal Laizhou Bay have obvious sources of terrigenous input. A previous research has shown the $\mathrm{Tl}$ concentrations ranged from 0.51 to $0.77 \mu \mathrm{g} \mathrm{g}^{-1}$, with an average of $0.69 \mu \mathrm{g} \mathrm{g}^{-1}$ in the surface sediments of the Bohai Bay, which is another major bay of the Bohai Sea like the Laizhou Bay (Duan et al., 2012). The Bohai Bay suffered more seriously from anthropogenic activities than the Laizhou Bay (Gao et al., 2014), which might cause the higher concentrations of $\mathrm{Tl}$ in the surface sediments of this Bay than the Laizhou Bay.

Due to the lack of $\mathrm{Tl}$ value in related environmental guidelines in China, the allowable maximum concentration of $\mathrm{Tl}\left(1.00 \mu \mathrm{g} \mathrm{g}^{-1}\right)$ in Canadian soil guideline was used to assess the extent of its

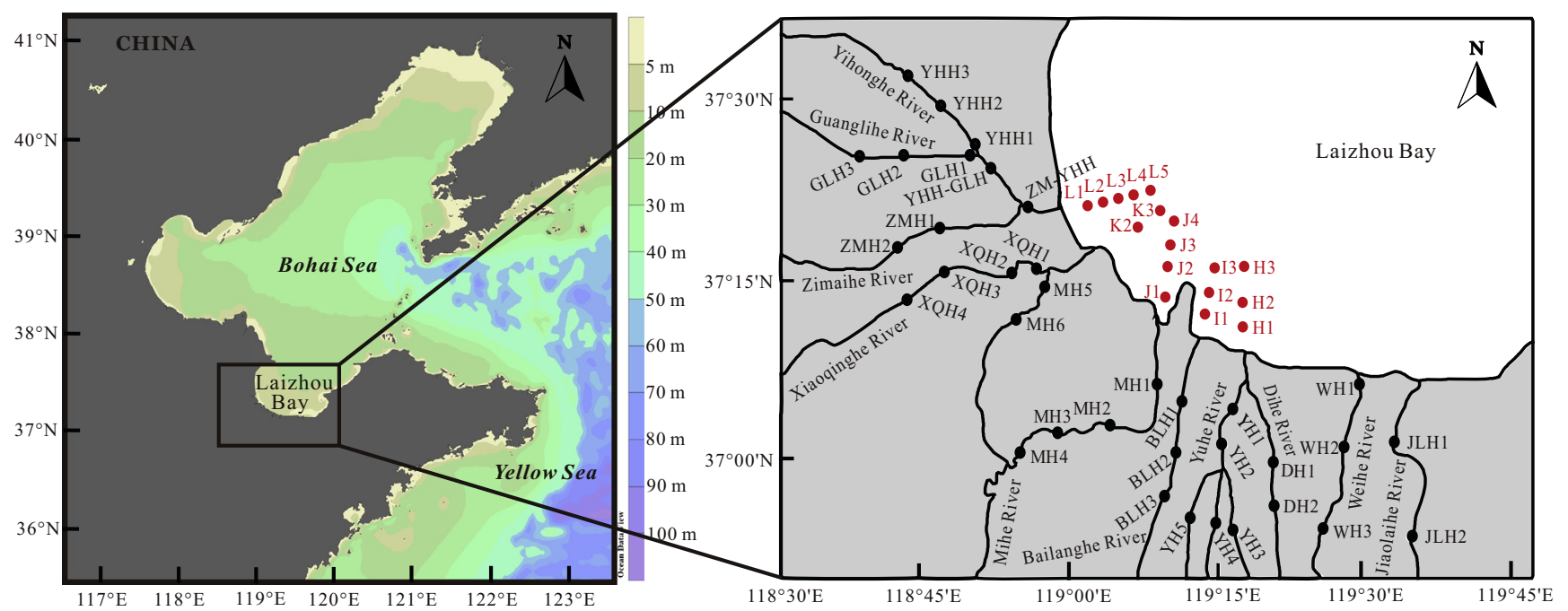

Fig. 1. Location of sampling sites in the southwestern coastal Laizhou Bay 


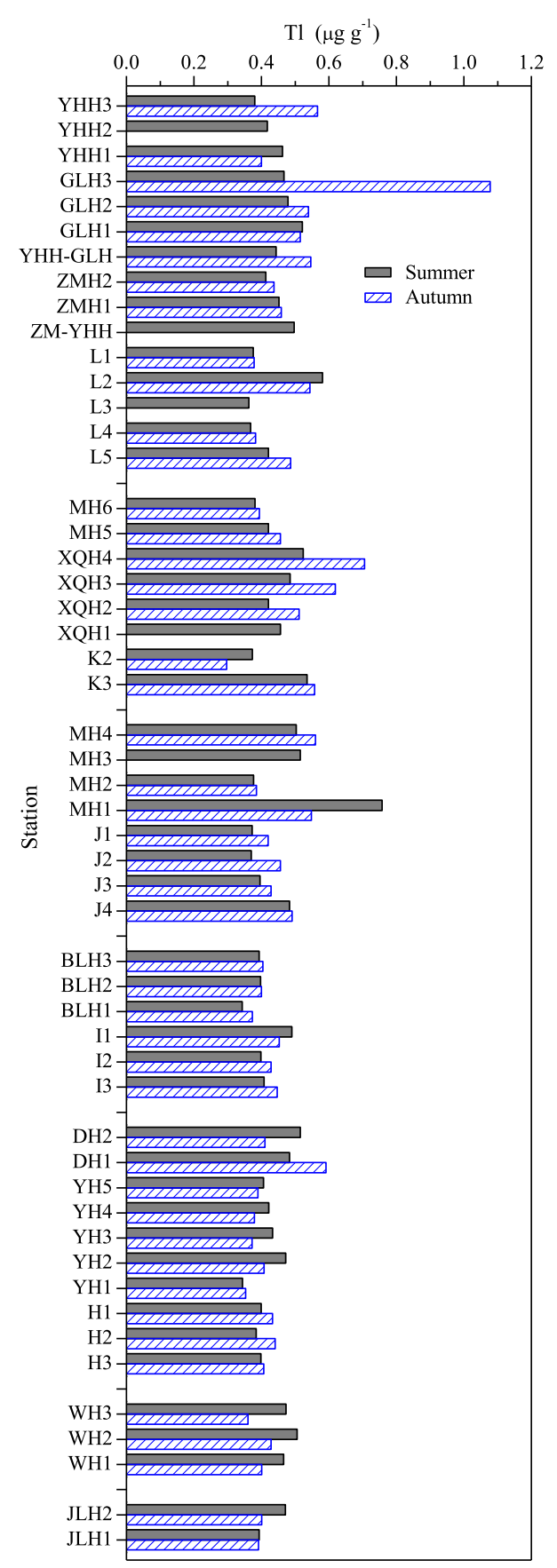

Fig. 2. The spatial variations of the $\mathrm{Tl}$ concentrations in the surface sediments of the southwestern coastal Laizhou Bay.

pollution in this study (CCME, 1999). Only the Tl concentration in the sample of site GLH3 in autumn $\left(1.08 \mu \mathrm{g} \mathrm{g}^{-1}\right)$ exceeded the corresponding Canadian soil standard. Researchers pointed out that the waste of metallurgical plants and the burning of fossil fuels could bring a lot of Tl (Kazantzis, 2000; Cheam, 2001), and site GLH3 was located at Dongying City, so the relatively higher Tl concentration seemed to be from these sources. However, this should be verified by EF and lithogenic source analysis. Overall, there was no obvious $\mathrm{Tl}$ pollution in surface sediments of the southwestern coastal Laizhou Bay.

To find out the relationships of $\mathrm{Tl}$ between the two sampling periods, a scatter graph was made for Tl concentrations (Fig. 3). There was a significant correlation $\left(P=0.55 \times 10^{-3}\right)$ between the concentrations of $\mathrm{Tl}$ in summer and the corresponding

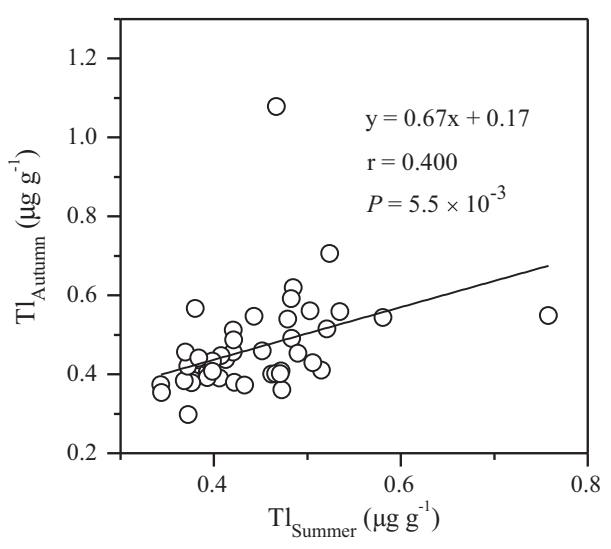

Fig. 3. Relationship between the concentrations of $\mathrm{Tl}$ in the surface sediments of the southwestern coastal Laizhou Bay in summer and autumn.

concentrations in autumn, indicating that their sources in the studied area were similar in different seasons. While reflected by the slope and intercept of the linear regression equation in Fig. 3, the emission intensity of sources between the two seasons was different to some extent. Discharge intensity, rainfall water, the hydrodynamic condition were all possible factors that cause this phenomenon.

The relationships between $\mathrm{Tl}$ and some geochemical parameters that may influence its spatial distribution are shown in Fig. 4. The whole data sets indicated that $\mathrm{Tl}$ had significant and positive correlations with the clay and silt fractions of sediments, and had a significant and negative correlation with the sand fraction, indicating that $\mathrm{Tl}$ was inclined to accumulate in fine-grained sediments. Other studies also found that $\mathrm{Tl}$ in sediments displayed a strong grain size controlling effect (Kabata, 1991; Duan et al., 2012).

Normally, the TOC is well correlated with heavy metals because natural organic matter has a high affinity through adsorption or complexation for heavy metals in the aquatic environment. But there was no significant correlation between the concentrations of Tl and TOC in this study. Liu et al. (2008) found that in deep sediments $(>20 \mathrm{~cm}$ ) of the Pearl River, Tl had significant positive correlation with TOC, because anaerobic microorganism had sharp metabolism in deep sediments, and a large number of sulfide and organic matter were accumulated; but in surface and middle sediments $(<20 \mathrm{~cm})$, Tl had significant positive correlation only with fine-grained components but not with TOC, like that of this study. Besides, there was evidence, which was discussed below, that $\mathrm{Tl}$ in surface sediments $(\sim 5 \mathrm{~cm})$ of the coastal Laizhou Bay was dominantly lithogenic. This may partly explain why $\mathrm{Tl}$ had no significant correlation with TOC in surface sediments of the coastal Laizhou Bay. In addition, hydrodynamic conditions in estuaries were very complicated, thus TOC was not a controlling factor of Tl distribution in the studied area.

Many studies showed that Fe oxides had strong adsorption and accumulation of Tl (Flegal et al., 1986; Tremel et al., 1997; Mueller, 2001; Duan et al., 2012). In this study, the whole data sets indicated that $\mathrm{Tl}$ had significant positive correlation $\left(P=1.3 \times 10^{-9}\right)$ with Fe oxides, which was consistent with previous studies. Moreover, Tl had significant positive correlation $\left(P=4.9 \times 10^{-8}\right)$ with $\mathrm{Al}$ oxides, which are signs of natural rock weathering sources (Duan et al., 2010), suggesting a substantial part of Tl was originated from continental detrital materials.

$\mathrm{EF}$ is a normalization technique frequently used to separate the metals of natural variability from the fraction that is associated with sediments due to anthropogenic activities (Gao and Chen, 2012). It is generally considered that an EF value of higher than 1.5 suggests that a significant portion of metal is delivered from 

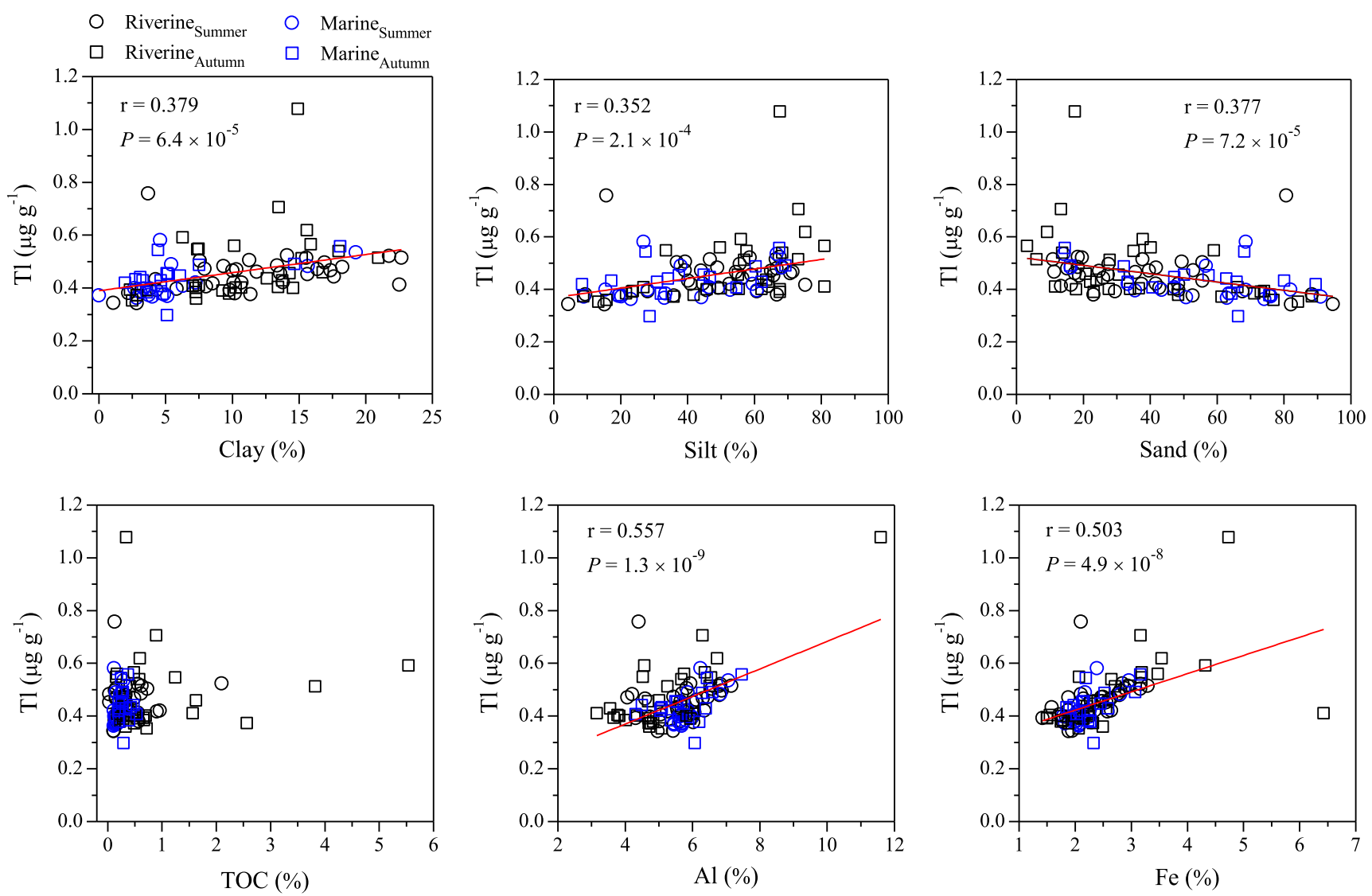

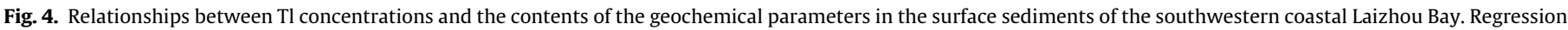
lines are based on the whole data set.

non-crustal materials and the sources are more likely to be anthropogenic (Feng, 2004). The EF for Tl was calculated to evaluate anthropogenic influence on $\mathrm{Tl}$ in sediments using the following formula (Alexander et al., 1993):

$\mathrm{EF}=\frac{\left(C_{\mathrm{Tl}} / C_{\mathrm{Al}}\right)_{\text {Sample }}}{\left(C_{\mathrm{Tl}} / C_{\mathrm{Al}}\right)_{\text {Background }}}$

where $C_{\mathrm{Tl}}$ and $C_{\mathrm{Al}}$ denote the concentrations of element $\mathrm{Tl}$ and $\mathrm{Al}$ in the samples and in the upper continental crust (UCC) (Taylor and McLennan, 1995), respectively. In this study, Al was used as the reference element for geochemical normalization because it represents the quantity of aluminosilicates which is generally the predominant carrier phase for metals in coastal sediments and its natural concentration tends to be uniform. The spatial distributions of calculated EFs for $\mathrm{Tl}$ were shown in Fig. 5.

The EF values of $\mathrm{Tl}$ in almost all the surface sediments of the coastal Laizhou Bay were less than 1.5 suggesting the accumulation of natural sources. Although the maximum concentration of $\mathrm{Tl}$ was found in GLH3 in autumn, the EF analysis indicated that the anthropogenic impact on Tl in GLH3 was not obvious. Thus the high value in this site might be from the crustal contribution or natural source. Only at site MH1 which was located at a chemical industrial base on the southwestern coast of the Laizhou Bay EF was higher than 1.5 in summer $(E F=1.85)$, showing a significant influence from anthropogenic source. But the determined concentration of $\mathrm{Tl}$ in this site $\left(0.76 \mu \mathrm{g} \mathrm{g}^{-1}\right)$ was still lower than the allowable maximum concentration of $\mathrm{Tl}$ in Canadian soil standard, and might hardly cause negative ecological effects.

Potential ecological risk factor $\left(E_{r}^{i}\right)$ was originally developed by Håkanson (1980) and is an index widely used in ecological risk assessments of heavy metals in sediments. According to this methodology, the $E_{r}^{i}$ of a given element is defined as:

$E_{r}^{i}=T_{r}^{i} \cdot C_{f}^{i}=T_{r}^{i} \cdot\left(C_{o}^{i} / C_{n}^{i}\right)$

where $T_{r}^{i}$ is the toxic-response factor for this element; $C_{f}^{i}, C_{o}^{i}$ and $C_{n}^{i}$ are the contamination factor, the concentration in the sediment and the background reference level for this element, respectively. According to Håkanson (1980), the following tiers are used for the $E_{r}^{i}$ value: (i) $E_{r}^{i} \leqslant 40$ (low risk); (ii) $40<E_{r}^{i} \leqslant 80$ (moderate risk); (iii) $80<E_{r}^{i} \leqslant 160$ (considerable risk); (iv) $160<E_{r}^{i} \leqslant 320$ (high risk); (v) $320<E_{r}^{i}$ (very high risk).

Up to now, there is no reference background value for $\mathrm{Tl}$ in the sediments of the Laizhou Bay. In order to keep consistent with the above EF analysis and to compare with the previous studies about the Laizhou Bay (Zhuang and Gao, 2013; Zhuang and Gao, 2014a, 2014b; Gao et al., 2015), the average Tl concentration in UCC was chosen as the reference background value. There is also no toxicresponse factor for $\mathrm{Tl}$ until now; but given that the toxicities of $\mathrm{Tl}$ on mammals and plants were higher than $\mathrm{Hg}$, the toxic-response factor of $\mathrm{Hg}\left(T_{r}^{i}=40\right)$ was used as the reference value for $\mathrm{Tl}$ in this study.

The spatial distributions of calculated $E_{r}^{i} \mathrm{~s}$ for $\mathrm{Tl}$ were shown in Fig. 6. $E_{r}^{i}$ values of only two sites (GLH3 and MH1) exceeded 40, but neither exceeded $80 . E_{r}^{i}$ value of site GLH3 in autumn was 57.51 and the corresponding value in site MH1 in summer was 40.43, which meant there might be moderate ecological risk in these two sites. Despite the low EF value in site GLH3 and the low concentration in site $\mathrm{MH} 1, \mathrm{Tl}$ concentrations in these two sites exceeded the background value observably. So some attention should be paid to these sites. The Ganglihe River and the Mihe 


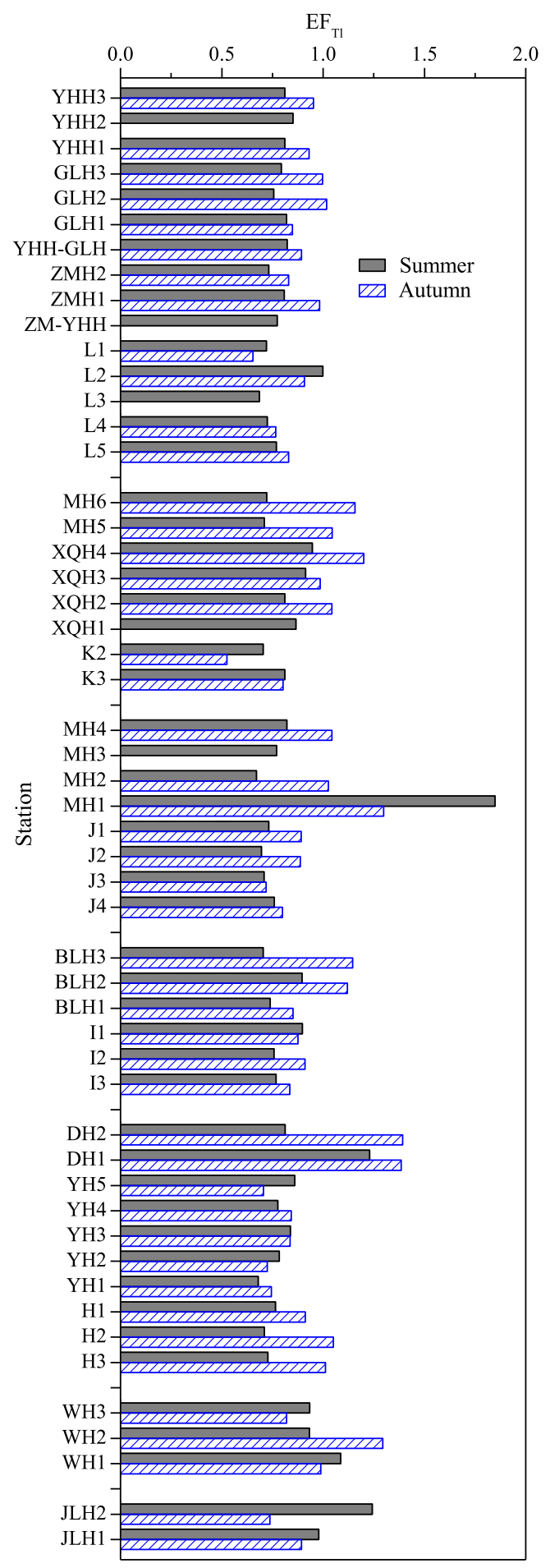

Fig. 5. The spatial variations of calculated $\mathrm{EFs}$ for $\mathrm{Tl}$ in the surface sediments of the southwestern coastal Laizhou Bay.

River flow through the urban areas of Dongying City and the chemical base located along the southwestern coastline of the Laizhou Bay, respectively. Therefore, $\mathrm{Tl}$ in the sites GLH3 and MH1 were probably from human activities. According to $E_{r}^{i}$ index, potential ecological risk posed by $\mathrm{Tl}$ was very low at all the rest of the sites $\left(E_{r}^{i} \leqslant 40\right)$. In summary, $\mathrm{Tl}$ in surface sediments might hardly cause any obvious ecological risk to the studied area.

$\mathrm{Tl}$ in the environment is accumulated partly from natural sources and partly from human activities. Lithogenic $\mathrm{Tl}\left(\mathrm{Tl}_{\mathrm{L}}\right)$ and non-lithogenic $\mathrm{Tl}\left(\mathrm{Tl}_{\mathrm{NL}}\right)$ could be the natural input and the non-natural input, respectively (Duan et al., 2012). Thus, the lithogenic and non-lithogenic parts of $\mathrm{Tl}$ were calculated in this study. The following formula was used for differentiating non-lithogenic from lithogenic Tl (Turekian and Wedepohl, 1961):

$\mathrm{Tl}_{\mathrm{NL}}=\mathrm{Tl}_{\text {total }}-\mathrm{Tl}_{\mathrm{L}}=\mathrm{Tl}_{\text {total }}-\left[\mathrm{Al}_{\text {total }}(\mathrm{Tl} / \mathrm{Al})_{\mathrm{UCC}}\right]$

The lithogenic $\mathrm{Tl}$ of each sample is the result of the measured total concentration of $\mathrm{Al}\left(\mathrm{Al}_{\text {total }}\right)$ times the $\mathrm{Tl} / \mathrm{Al}$ ratio for global average shale or crust; the non-lithogenic $\mathrm{Tl}$ was calculated as the difference between the total and lithogenic Tl (Turekian and Wedepohl, 1961). This calculation assumed that all Al was of lithogenic origin rather than the result of scavenging or biogenic production (Duan et al., 2012). In this study, the UCC was used as the lithogenic reference. Results indicated that there was a small

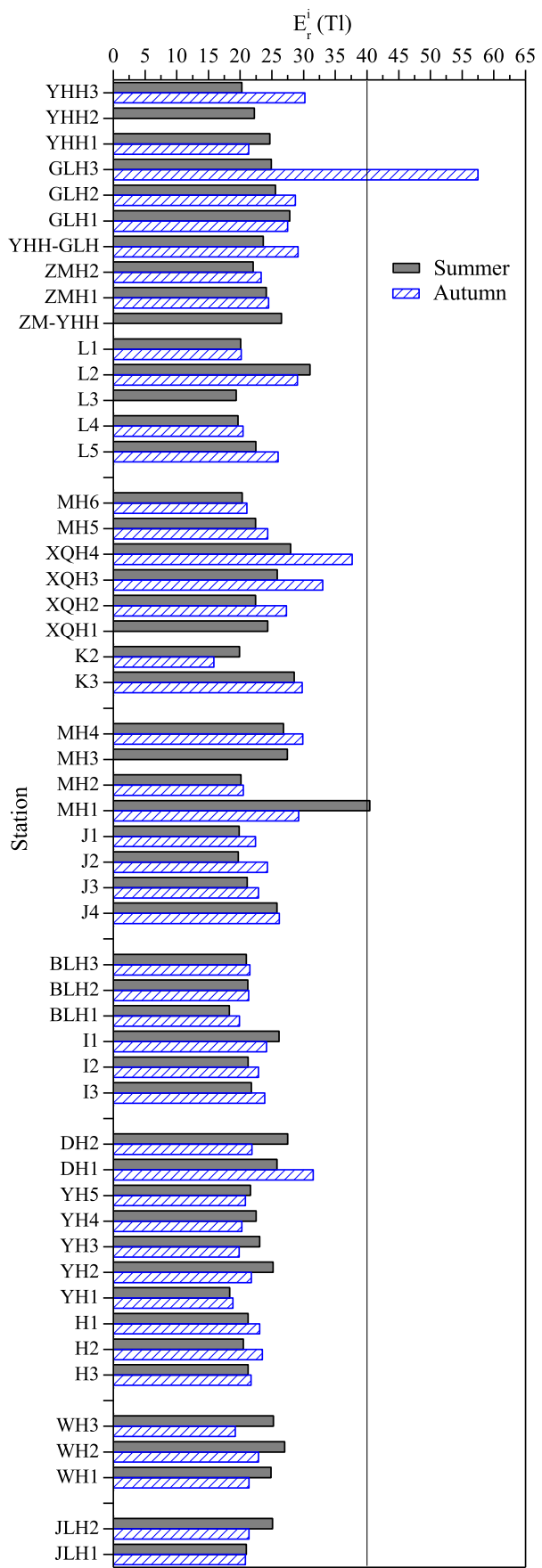

Fig. 6. The spatial variations of calculated $E_{r}^{i} \mathrm{~s}$ for $\mathrm{Tl}$ in the surface sediments of the southwestern coastal Laizhou Bay. The vertical line represents $E_{r}^{i}$ value of 40 . 
amount of non-lithogenic $\mathrm{Tl}$ ranging from $\approx 0$ to $0.35 \mu \mathrm{g} \mathrm{g}^{-1}$ with a mean value of $0.011 \mu \mathrm{g} \mathrm{g}^{-1}$ in summer, which on average accounted for $2.4 \%$ of the total $\mathrm{Tl}$ concentration in the samples; in autumn, the corresponding data were from $\approx 0$ to $0.16 \mu \mathrm{g} \mathrm{g}^{-1}$ and $0.019 \mu \mathrm{g} \mathrm{g}^{-1}$, which on average accounted for $4.0 \%$ of the total $\mathrm{Tl}$ concentration in the samples. The maximum values were recorded in sites $\mathrm{MH} 1$ and $\mathrm{DH} 1$ in summer and autumn, respectively; contents of non-lithogenic $\mathrm{Tl}$ in surface sediments in the marine area were almost negligible. Therefore, $\mathrm{Tl}$ in surface sediments of the southwestern coastal Laizhou Bay were mainly from the natural input with the non-natural input as an subsidiary source. So we speculate that the possible routes for $\mathrm{Tl}$ to enter the coastal surface sediments of the Laizhou Bay could be mainly from riverine input and atmospheric transport and deposition of natural matters.

\section{Acknowledgements}

This study was co-supported by the National Natural Science Foundation of China (41376083) and the Natural Science Foundation of Shandong Province, China (ZR2014DP005). We thank Yong Zhang, Peimiao Li, Jinfeng Zhang and Fengxia Zhou who participated in the sample collection for their assistance.

\section{References}

Alexander, C.R., Smith, R.G., Calder, F.D., Schropp, S.J., Windom, H.L., 1993. The historical record of metal enrichments in two Florida estuaries. Estuaries 16, 627-637.

CCME (Canadian Council of Ministers of the Environment), 1999. Canadian Soil Quality Guidelines for the Protection of Environmental and Human Health (available at <http://ceqg-rcqe.ccme.ca/en/index.html\#void>).

Cheam, V., 2001. Thallium contamination of water in Canada. Water Qual. Res. J. Can. 36 (4), 851-877.

Duan, L.Q., Song, J.M., Xu, Y.Y., Li, X.G., Zhang, Y., 2010. The distribution, enrichment and source of potential harmful elements in surface sediments of Bohai Bay, North China. J. Hazard. Mater. 183, 155-164.

Duan, L.Q., Song, J.M., Li, X.G., Yuan, H.M., Li, N., Xu, Y.Y., 2012. Thallium concentrations and sources in the surface sediments of Bohai Bay. Mar. Environ. Res. 73, 25-31.

Feng, H., Han, X., Zhang, W., Yu, L., 2004. A preliminary study of heavy metal contamination in Yangtze River intertidal zone due to urbanization. Mar. Pollut. Bull. 49, 910-915.

Flegal, A.R., Settle, D.M., Patterson, C.C., 1986. Thallium in marine plankton. Mar Biol. 90, 501-503.
Gao, B., Sun, K., Ren, M.Z., Liang, X.R., Peng, P.A., Sheng, G.Y., Fu, J.M., 2008. Ecological risk assessment of thallium pollution in the surface sediment of Beijiang River. Ecol. Environ. 17 (2), 528-532 (in Chinese with English abstract).

Gao, X.L., Chen, C.T.A., 2012. Heavy metal pollution status in surface sediments of the coastal Bohai Bay. Water Res. 46 (6), 1901-1911.

Gao, X.L., Chen, C.T.A., Wang, G., Xue, Q.Z., Tang, C., Chen, S.Y., 2010. Environmental status of Daya Bay surface sediments inferred from a sequential extraction technique. Estuar. Coast. Shelf Sci. 86 (3), 369-378.

Gao, X.L., Zhou, F.X., Chen, C.T.A., 2014. Pollution status of the Bohai Sea, China: an overview of the environmental quality assessment related trace metals. Environ. Int. 62, 12-30.

Gao, X.L., Zhuang, W., Chen, C.T.A., Zhang, Y., 2015. Sediment quality of the SW coastal Laizhou Bay, Bohai Sea, China: a comprehensive assessment based on the analysis of heavy metals. PLoS ONE 10 (3), e0122190.

Håkanson, L., 1980. An ecological risk index for aquatic pollution control. A sedimentological approach. Water Res. 14, 975-1001.

Hsieh, C.Y., Tsai, M.H., Ryan, D.K., Pancorbo, O.C., 2004. Toxicity of the 13 priority pollutant metals to Vibrio fisheri in the Microtox ${ }^{\circledR}$ chronic toxicity test. Sci. Total Environ. 320, 37-50.

Kabata, P.A., 1991. Trace metals in soils of Poland: occurrence and behavior. Trace Subst. Environ. Health 25, 53-70.

Kazantzis, G., 2000. Thallium in the environment and health effects. Environ. Geochem. Health 22, 275-280.

Liu, J., Zhang, P., Chen, Y.H., Qi, J.Y., Wang, J., Wang, C.L., Wang, X.Y., 2008. Determination of thallium chemical form in sediment core from Pearl River. J. Guangzhou Univ. 7, 67-70 (in Chinese with English abstract).

Mueller, R.F., 2001. Microbially mediated thallium immobilization in Bench Scale system. Mine Water Environ. 20, 17-29.

Taylor, S.R., McLennan, S.M., 1995. The geochemical evolution of the continental crust. Rev. Geophys. 33 (2), 241-265.

Tremel, A., Masson, P., Garraud, H., Donard, O.F., Baize, D., Mench, M., 1997. Thallium in French agrosystems-II. Concentration of thallium in field-grown rape and some other plant species. Environ. Pollut. 97, 161-168.

Turekian, K.K., Wedepohl, K.H., 1961. Distribution of the elements in some major units of the earth's crust. Geol. Soc. Am. Bull. 72, 175-192.

USEPA, 1979. Water related fate of the 129 priority pollutants. Washington, D.C., USA.

Zhuang, W., Gao, X.L., 2013. Acid-volatile sulfide and simultaneously extracted metals in surface sediments of the southwestern coastal Laizhou Bay, Bohai Sea: concentrations, spatial distributions and the indication of heavy metal pollution status. Mar. Pollut. Bull. 76 (1-2), 128-138.

Zhuang, W., Gao, X.L., 2014a. Assessment of heavy metal impact on sediment quality of the Xiaoqinghe estuary in the coastal Laizhou Bay, Bohai Sea: inconsistency between two commonly used criteria. Mar. Pollut. Bull. 83 (1), 352-357.

Zhuang, W., Gao, X.L., 2014b. Integrated assessment of heavy metal pollution in the surface sediments of the Laizhou Bay and the coastal waters of the Zhangzi Island, China: comparison among typical marine sediment quality indices. PLoS ONE 9 (4), e94145.

Zhuang, W., Gao, X.L., Zhang, Y., Xing, Q.G., Tosi, L., Qin, S., 2014. Geochemical characteristics of phosphorus in surface sediments of two major Chinese mariculture areas: the Laizhou Bay and the coastal waters of the Zhangzi Island. Mar. Pollut. Bull. 83 (1), 343-351. 